\title{
Is A163G Polymorphism in the Osteoprotegerin Gene Associated with Heel Velocity of Sound in Postmenopausal Women?
}

\author{
K. ZAJÍČKOVÁ, A. ZEMANOVÁ, M. HILL, I. ŽOFKOVÁ \\ Institute of Endocrinology, Prague, Czech Republic
}

Received November 12, 2007

Accepted January 28, 2008

On-line February 13, 2008

\section{Summary}

Osteoprotegerin (OPG) plays an important inhibitory role in osteoclastogenesis. Polymorphisms in the $O P G$ gene recently have been associated with various bone phenotypes including fractures. The aim of the present study was to investigate the association between three informative $O P G$ polymorphisms and quantitative ultrasound variables of the heel. In a cohort of 165 perimenopausal women polymorphisms in the $O P G$ promoter (A163G, T245G) and in exon 1 (G1181C) were assessed by PCRRFLP analysis. The distribution of the investigated genotypes was similar to other Caucasian women (A163G-AA $68 \%$, AG $30 \%$, GG $2 \%$, T245G-TT $84.4 \%$, TG $15 \%$, GG $0.6 \%$, G1181C- GG 22 $\%$, CG $55 \%$, CC $23 \%$ ). After adjustment for body mass index and years since menopause, in a subgroup of 87 postmenopausal subjects, calcaneal velocity of sound (VOS, $\mathrm{m} / \mathrm{s}$ ) was significantly associated with A163G polymorphism ( $p=0.0102$, ANCOVA). Women with the presence of $G$ allele ( $A G+G G$ genotypes) had significantly lower VOS than women with AA genotype. Neither T245G nor G1181C were associated with calcaneal ultrasound indices. In conclusion, A163G polymorphism was significantly associated with VOS at the heel in a limited cohort of postmenopausal women. The present study replicated in part the previous findings about $O P G$ gene variations and peripheral bone mass in Caucasian women.

\section{Key words}

Osteoprotegerin gene - Polymorphisms - VOS • BUA • Menopause

\section{Corresponding author}

K. Zajičková, Institute of Endocrinology, Národní třída 8, 11694 Prague 1, Czech Republic. E-mail: kzajickova@endo.cz

\section{Introduction}

Calcaneal quantitative ultrasound (QUS) provides two measures: velocity of sound (VOS, $\mathrm{m} / \mathrm{s}$ ) and broadband ultrasound attenuation (BUA, $\mathrm{dB} / \mathrm{MHz}$ ). In vitro studies of cancellaneous bone have shown that BUA is associated with trabecular bone structure whereas VOS depends on elasticity and density of the bone (Bouxsein et al. 1997). Both ultrasound parametres are correlated with bone mineral density (BMD, $\mathrm{g} / \mathrm{cm}^{2}$ ). QUS parametres along with BMD predict osteoporotic fracture risk (Hartl et al. 2002). However, this association remains significant even after adjustment for BMD at particular sites of the skeleton. This fact indicates that QUS measurements may capture other aspects of bone structure and strength than bone densitometry (DXA) does (Lee et al. 2004).

Moreover, recent twin and family studies have indicated that a large proportion of QUS variability is determined by genetic factors. Heritable estimates for calcaneal BUA ranged from 0.5-0.7 and from 0.5 to 0.6 for VOS (Arden et al. 1996, Knapp et al. 2003, Lee et al. 2004).

Accelerated bone resorption contributes in large to postmenopausal bone loss. Candidate genes for local or systemic calciotropic factors involved in bone remodeling may play a role in the genetic variability of the bone phenotypes (Liu et al. 2006). Osteoprotegerin (OPG), a member of the tumor necrosis factor (TNF) and TNF receptor superfamily, plays an important inhibitory role in osteoclastogenesis. The activation and differentiation of osteoclasts through receptor activator of nuclear factor$\mathrm{KB}$ ligand (RANKL) is neutralized by the decoy receptor

PHYSIOLOGICAL RESEARCH • ISSN 0862-8408 (print) • ISSN 1802-9973 (online)

(c) 2008 Institute of Physiology v.v.i., Academy of Sciences of the Czech Republic, Prague, Czech Republic

Fax +420 241062 164, e-mail: physres@biomed.cas.cz, www.biomed.cas.cz/physiolres 
OPG (Khosla 2001). Injected OPG can thus prevent bone resorption in humans (Khosla 2001). Various upstream regulators of the bone metabolism (e.g. estrogens, leptin) induce an imbalance between OPG and RANKL activation which results in either bone loss or accrual (Khosla 2001). Sequence variations in the genes involved in the RANKL/RANK/OPG bone remodeling pathway might be, therefore, associated with different bone phenotypes (Gallo et al. 2007).

The $O P G$ promotor region represents a target sequence for various calciotropic factors regulating $O P G$ gene expression. Polymorphisms in this and nearby regions may contribute to genetic regulation of bone mass. Various single nucleotide polymorphisms (SNP) in the $O P G$ gene have been inconsistently associated with BMD or fractures (Arko et al. 2002, Langdahl et al. 2002, Jorgensen et al. 2004). A recent study of Caucasian postmenopausal women has demonstrated that A $163 \mathrm{G}$ polymorphism, localized in the $O P G$ promotor, has been related to peripheral indices of bone mass (Jorgensen et al. 2004).

The aim of the present study was to investigate the association between three informative polymorphisms in the regulatory region of the $O P G$ gene and quantitative ultrasound variables of the heel in a cohort of postmenopausal women.

\section{Methods and Materials}

\section{Population}

The genotyping was carried out in a cohort of 165 peri- and postmenopausal unrelated women of Caucasian origin. A subset of 113 ambulatory postmenopausal women $(62.4 \pm 8.97$ years of age and $13.3 \pm 8.35$ years since menopause (YSM)) underwent QUS measurements (Table 1).

The women were recruited through the screening of diseases associated with menopause including osteoporosis. None of the investigated women had history of early or late menarche or menopause. All subjects had normal calcium and protein intake; none was markedly underweight or obese, with the mean body mass index (BMI) $25.7 \pm 3.51 \mathrm{~kg} / \mathrm{m}^{2}$ (Table 1). The study group did not include any alcoholics, heavy smokers, women with active endocrinopathy or severe internal disease or those treated with calciotropic drugs including estrogen and vitamin D.

Informed consent was obtained from all of the women, and all procedures were approved by the Ethical
Table 1. Baseline demographic and quantitative ultrasound characteristics of the study population.

\begin{tabular}{lcc}
\hline Demographic data & n & \\
\hline Age (years) & 113 & $62.4 \pm 8.97$ \\
YSM (years) & 113 & $13.3 \pm 8.35$ \\
BMI & 113 & $25.7 \pm 3.51$ \\
Calcaneal quantitative ultrasound & \\
BUA (Db/MHz) & 113 & $66.9 \pm 18.5$ \\
VOS (m/s) & 87 & $1603 \pm 50.8$ \\
Stifness index & 87 & $73.6 \pm 22.8$ \\
\hline
\end{tabular}

Results are given as mean \pm S.D.

Committee of the Institute of Endocrinology, Prague.

Calcaneal quantitative ultrasound measurements

Calcaneal QUS was measured at the right heel using a dry contact ultrasound scanner (CubaClinical, UK). The coefficient of variation for BUA was $3.04 \%$, for $\operatorname{VOS} 0.24 \%$. The quantitative ultrasound index, called „stiffness index“, was calculated as a linear combination of BUA and VOS (Genant et al. 1996).

\section{Genotyping}

Genomic DNA was isolated from peripheral leukocytes by a standard salt extraction procedure (Miller et al. 1988). All SNPs were assessed by a restriction analysis of the PCR products as described elsewhere (Langdahl et al. 2002).

\section{Stastistics}

In both $\mathrm{A} 163 \mathrm{G}$ and $\mathrm{T} 246 \mathrm{G}$ polymorphisms, due to the low frequency of GG genotypes, the AG with GG and TG with GG genotypes were pooled together, respectively. Differences in QUS measures within the $O P G$ genotypes were evaluated by ANCOVA after adjustment for BMI and YSM. Statistics were done using the Statgraphics plus v.5.1 software from Manugistics (Rockville, MA, USA). Data are expressed as median and lower-upper quartile in Table 3 or as mean \pm S.D. in Table 1. Chi-square $\left(\chi^{2}\right)$ formula was used to test for Hardy-Weinberg equilibrium and to detect differences from the expected frequencies.

\section{Results}

The distribution of the investigated genotypes 
Table 2. A163G, T245G and G1181C polymorphisms in the OPG gene: genotype distribution, allele frequency and parametres of HardyWeinberg equilibrium in a cohort of 165 perimenopausal women.

\begin{tabular}{|c|c|c|c|c|c|c|c|c|c|}
\hline \multirow[t]{2}{*}{$\begin{array}{l}\text { SNP } \\
\text { dbSNP reference number }\end{array}$} & \multicolumn{3}{|c|}{$\begin{array}{c}\text { A163G } \\
\text { rs3102735 }\end{array}$} & \multicolumn{3}{|c|}{$\begin{array}{c}\text { T245G } \\
\text { rs3134069 }\end{array}$} & \multicolumn{3}{|c|}{$\begin{array}{c}\text { G1181C } \\
\text { rs2073618 }\end{array}$} \\
\hline & AA & 112 & $68 \%$ & $\mathrm{TT}$ & 139 & $84.4 \%$ & GG & 37 & $22 \%$ \\
\hline \multirow[t]{2}{*}{ Genotype distribution } & $\mathrm{AG}$ & 50 & $30 \%$ & TG & 25 & $15 \%$ & CG & 90 & $55 \%$ \\
\hline & GG & 3 & $2 \%$ & GG & 1 & $0.6 \%$ & $\mathrm{CC}$ & 38 & $23 \%$ \\
\hline Allele frequency and & $\mathrm{A}$ & 0.83 & $\chi^{2}=0.963$ & $\mathrm{~T}$ & 0.92 & $\chi^{2}=0.014$ & G & 0.497 & $\chi^{2}=1.356$ \\
\hline Hardy-Weinberg equilibrium & $\mathrm{G}$ & 0.17 & $\pi \geq 0.50$ & G & 0.082 & $\pi \geq 0.90$ & $\mathrm{C}$ & 0.503 & $\pi \geq 0.50$ \\
\hline
\end{tabular}

Table 3. Calcaneal quantitative ultrasound parameters in relation to the A163G genotypes.

\begin{tabular}{|c|c|c|c|c|c|c|c|}
\hline & \multicolumn{6}{|c|}{ A163G } & \multirow[b]{2}{*}{$p$ (ANCOVA) } \\
\hline & $\mathbf{n}$ & & $\mathbf{A A}$ & $\mathbf{n}$ & & $\mathbf{A G}+\mathbf{G G}$ & \\
\hline$B U A(D b / M H z)$ & 77 & 66 & $(54-78)$ & 36 & 58 & $(52.25-67.5)$ & NS \\
\hline $\operatorname{VOS}(\mathrm{m} / \mathrm{s})$ & 63 & 1603 & $(1575-1636)$ & 24 & 1569 & $(1540-1615)$ & 0.0102 \\
\hline Stifness index & 63 & 72.51 & $(61.07-84.04)$ & 24 & 59.45 & (49.04-76.58) & NS \\
\hline
\end{tabular}

Results are expressed as median (lower-upper quartile). $p$ values are by ANCOVA.

did not deviate from Hardy-Weinberg equilibrium and was similar to other Caucasian women (Table 2) (Langdahl et al. 2002, Jorgensen et al. 2004, Ueland et al. 2007). In a subgroup of 87 women who underwent QUS measurements, A163G polymorphism was significantly associated with calcaneal $\operatorname{VOS}(\mathrm{p}=0.0102$, ANCOVA) (Table 3). Women with the presence of $G$ allele $(A G+G G$ genotypes) had significantly lower VOS than women with AA genotype. The statistic analysis was carried out after adjustment for BMI and YSM. Similar results between A163G and BUA were observed, however, this trend did not reach significance (Table 3).

Neither T245G nor G1181C were associated with any calcaneal ultrasound indices (data not shown).

\section{Discussion}

In the present study we investigated three informative polymorphisms from the regulatory region of the $O P G$ gene including promotor $\mathrm{A} 163 \mathrm{G}$ and $\mathrm{T} 245 \mathrm{G}$ variations with a nonsynonymous polymorphism in exon 1 (G1181C). A significant association between A163G polymorphism and calcaneal VOS was found in the present limited cohort of postmenopausal women.

Twin and family studies have shown that QUS measures are highly heritable (Arden et al. 1996, Lee et al. 2004, Liu et al. 2006). Menopause seems to play a lesser role in overall QUS variability in comparison with BMD (Hunter et al. 2001). Additionally, underlying genetic factors contributing to QUS variations might be in part unique, unshared with those involved in BMD regulation (Knapp et al. 2003, Lee et al. 2006).

Several recent publications have addressed the hypothesis that polymorphisms in the regulatory region at the $5^{\prime}$ end of the $O P G$ gene may contribute to the genetic regulation of various bone phenotypes. In a study of Lagdahl et al. (2002) the OPG gene has been sequenced and consequently 12 polymorphisms have been described. The majority of them have been, however, in a complete linkage. For further analysis, five informative polymorphisms have been selected. Genotypes with the rare $\mathrm{G}$ allele (A163G and $\mathrm{T} 245 \mathrm{G}$ ) have significantly prevailed in patients with vertebral fractures in comparison with controls. In the same cohort, these genotypes have not been related to BMD or biochemical markers of bone turnover (Langdahl et al. 2002). These findings implicate that $O P G$ polymorphisms might be associated with bone quality parametres others that bone mineral density or biochemical turnover. A significant association between A163G polymorphism, hip and wrist fractures has been confirmed in another study in Caucasian postmenopausal women (Jorgensen et al. 
2004). Moreover, A163G genotypes have been associated with low peripheral bone mass assessed either by DXA at the distal radius or by QUS at the heel. In genotypes with unfavourable $\mathrm{G}$ allele lower BMD, calcaneal BUA and VOS have been found. The effect of A163G polymorphism on bone mass was not mediated through serum OPG levels as might be expected (Jorgensen et al. 2004). A twin study has demonstrated that, unlikely BMD or QUS, circulating OPG levels were almost exclusively determined by environment (Abrahamsen $e t$ al. 2005). These findings, however, do not exclude that local, paracrine OPG concentrations may vary within the bone microenvironment between the $O P G$ genotypes. Functional in vitro analysis might therefore clarify why the presence of $\mathrm{G}$ allele (A163G), in particular, has been associated with deteriorated bone phenotypes.

On the other hand, negative associations on $O P G$ polymorphisms have also been presented. In a large group of elderly Australian women of Caucasian origin none of the $O P G$ polymorphisms have been associated with any of the DXA or QUS measurements (Ueland $e t$ al. 2007). The study, which had negative results, was carried out on a well-described large cohort of Australian elderly women, thus providing sufficient power to detect minor genetic contribution to overall trait variability. Different genetic background of investigated cohorts might explain divergent results.
In the present study a significant association between A163G polymorphism and VOS was demonstrated. Subjects with the presence of $G$ allele (AG+GG genotypes) had significantly lower VOS than women with AA genotype. Similar results were found for BUA, however this trend did not reach statistical significance. These discordant findings probably do not have any physiological relevance but may very likely reflect false negative results due to the limited size of the study cohort (Brown 2005). Further studies are therefore necessary in a larger general population to confirm the relationship between $\mathrm{A} 163 \mathrm{G}$ polymorphism and bone ultrasound indices.

In conclusion, $\mathrm{A} 163 \mathrm{G}$ polymorphism in the $O P G$ gene was significantly associated with VOS at the heel in a small, well-characterized cohort of postmenopausal women. The present study replicated in part the previous findings about $O P G$ gene variations and peripheral bone mass in Caucasian women.

\section{Conflict of Interest}

There is no conflict of interest.

\section{Acknowledgements}

The study was supported by the grant No. NR/7827-3 from the Internal Agency of the Ministry of Health of the Czech Republic.

\section{References}

ABRAHAMSEN B, HJELMBORG JV, KOSTENUIK P, STILGREN LS, KYVIK K, ADAMU S, BRIXEN K, LANGDAHL BL: Circulating amounts of osteoprotegerin and RANK ligand: genetic influence and relationship with BMD assessed in female twins. Bone 36: 727-735, 2005.

ARDEN NK, BAKER J, HOGG C, BAAN K, SPECTOR TD: The heritability of bone mineral density, ultrasound of the calcaneus and hip axis length: a study of postmenopausal twins. J Bone Miner Res 11: 530-534, 1996.

ARKO B, PREZELJ J, KOMEL R, KOCIJANCIC A, HUDLER P, MARC J: Sequence variations in the osteoprotegerin gene promoter in patients with postmenopausal osteoporosis. $J$ Clin Endocrinol Metab 87: 4080-4084, 2002.

BOUXSEIN ML, RADLOFF SE: Quantitative ultrasound of the calcaneus reflects the mechanical properties of calcaneal trabecular bone. J Bone Miner Res 12: 839-846, 1997.

BROWN MA: Genetic studies of osteoporosis--a rethink required. Calcif Tissue Int 76: 319-325, 2005.

GALLO J, RAŠKA M, MRÁZEK F: Bone remodelling, particle disease and individual susceptibility to periprosthetic osteolysis. Physiol Res 2008 [In press].

GENANT HK, ENGELKE K, FUERST T, GLUER CC, GRAMPP S, HARRIS ST, JERGAS M, LANG T, LU Y, MAJUMDAR S, MATHUR A, TAKADA M: Noninvasive assessment of bone mineral and structure: state of the art. $J$ Bone Miner Res 11: 707-730, 1996. 
HARTL F, TYNDALL A, KRAENZLIN M, BACHMEIER C, GUCKEL C, SENN U, HANS D, THEILER R: Discriminatory ability of quantitative ultrasound parameters and bone mineral density in a population-based sample of postmenopausal women with vertebral fractures: results of the Basel Osteoporosis Study. $J$ Bone Miner Res 17: 321-330, 2002.

HUNTER DJ, DE LANGE M, ANDREW T, SNIEDER H, MACGREGOR AJ, SPECTOR TD: Genetic variation in bone mineral density and calcaneal ultrasound: a study of the influence of menopause using female twins. Osteoporos Int 12: 406-411, 2001.

JORGENSEN HL, KUSK P, MADSEN B, FENGER M, LAURITZEN JB: Serum osteoprotegerin (OPG) and the A163G polymorphism in the OPG promoter region are related to peripheral measures of bone mass and fracture odds ratios. J Bone Miner Metab 22: 132-138, 2004.

KHOSLA S: Minireview: the OPG/RANKL/RANK system. Endocrinology 142: 5050-5055, 2001.

KNAPP KM, ANDREW T, MACGREGOR AJ, BLAKE GM, FOGELMAN I, SPECTOR TD: An investigation of unique and shared gene effects on speed of sound and bone density using axial transmission quantitative ultrasound and DXA in twins. J Bone Miner Res 18: 1525-1530, 2003.

LANGDAHL BL, CARSTENS M, STENKJAER L, ERIKSEN EF: Polymorphisms in the osteoprotegerin gene are associated with osteoporotic fractures. J Bone Miner Res 17: 1245-1255, 2002.

LEE M, CZERWINSKI SA, CHOH AC, TOWNE B, DEMERATH EW, CHUMLEA WC, SUN SS, SIERVOGEL RM: Heritability of calcaneal quantitative ultrasound measures in healthy adults from the Fels Longitudinal Study. Bone 35: 1157-1163, 2004.

LEE M, CZERWINSKI SA, CHOH AC, DEMERATH EW, SUN SS, CHUMLEA WC, TOWNE B, SIERVOGEL RM: Unique and common genetic effects between bone mineral density and calcaneal quantitative ultrasound measures: the Fels Longitudinal Study. Osteoporos Int 17: 865-871, 2006.

LIU YJ, SHEN H, XIAO P, XIONG DH, LI LH, RECKER RR, DENG HW: Molecular genetic studies of gene identification for osteoporosis: a 2004 update. J Bone Miner Res 21: 1511-1535, 2006.

MILLER SA, DYKES DD, POLESKY HF: A simple salting out procedure for extracting DNA from human nucleated cells. Nucleic Acids Res 16: 1215, 1988.

UELAND T, BOLLERSLEV J, WILSON SG, DICK IM, ISLAM FM, MULLIN BH, DEVINE A, PRINCE RL: No associations between OPG gene polymorphisms or serum levels and measures of osteoporosis in elderly Australian women. Bone 40: 175-181, 2007. 